\title{
Reactive extractive electrospray ionization tandem mass spectrometry for sensitive detection of tetrabromobisphenol A derivatives
}

\author{
Yong Tian ${ }^{\mathrm{a}}$, Jian Chen ${ }^{\mathrm{b}}$, Yong-zhong Ouyang ${ }^{\mathrm{b}}$, Guang-bo $\mathrm{Qu}^{\mathrm{a}}, \mathrm{Ai}$-feng Liu ${ }^{\mathrm{a}}$, \\ Xue-mei Wang ${ }^{\mathrm{a}}$, Chun-xiao Liu ${ }^{\mathrm{a}}$, Jian-bo Shi ${ }^{\mathrm{a}, *}{ }^{*}$, Huan-wen Chen ${ }^{\mathrm{b}}$, Gui-bin Jiang ${ }^{\mathrm{a}}$ \\ a State Key Laboratory of Environmental Chemistry and Ecotoxicology, Research Center for Eco-Environmental Sciences, Chinese Academy of Sciences, \\ Beijing 100085, China \\ b Jiangxi Key Laboratory for Mass Spectrometry and Instrumentation, College of Chemistry, Biology and Material Sciences, \\ East China Institute of Technology, Nanchang, 330013, China
}

\section{H I G H L I G H T S}

- A high ionization efficiency method for TBBPA derivatives detection was developed.

- Trace levels $\left(0.05 \mu \mathrm{g} \mathrm{L}^{-1}\right)$ of TBBPA derivatives can be detected directly.

- A single detection needs only 1 min.

- Provide more possibilities for low polar molecules detection by MS.

\section{A R T I C L E I N F O}

\section{Article history:}

Received 29 October 2013

Received in revised form 9 January 2014

Accepted 10 January 2014

Available online 19 January 2014

\section{Keywords:}

Tetrabromobisphenol A derivatives

Silver ion

Mass spectrometry

Reactive ionization

Waste water

\section{G R A P H I C A L A B S T R A C T}
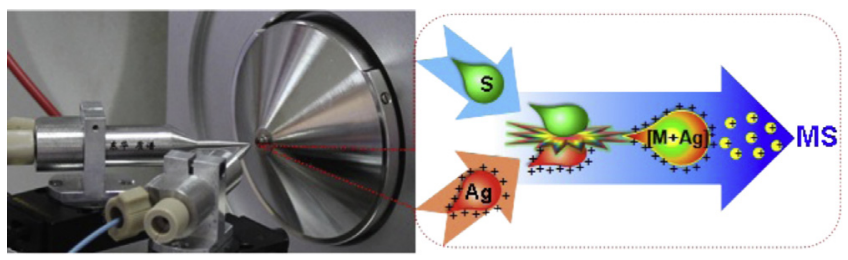

\begin{abstract}
A B S T R A C T
Sensitive detection of tetrabromobisphenol A (TBBPA) and its derivatives, a group of emerging toxic contaminants, is highly necessitated in environmental investigation. Herein a novel analytical strategy based on reactive extractive electrospray ionization (EESI) tandem mass spectrometry for detection of tetrabromobisphenol A bis(2-hydroxyethyl ether) (TBBPA-BHEE), tetrabromobisphenol A bis(glycidyl ether) (TBBPA-BGE), tetrabromobisphenol A bis(allylether) (TBBPA-BAE), and tetrabromobisphenol $S$ bis(allylether) (TBBPS-BAE) in industrial waste water samples was developed. Active silver cations $\left(\mathrm{Ag}^{+}\right)$, generated by electrospraying a silver nitrate methanol solution $\left(10 \mathrm{mg} \mathrm{L}^{-1}\right)$, collides the neutral TBBPA derivatives molecules in the EESI source to form $[\mathrm{M}+\mathrm{Ag}]^{+}$complexes of the analytes under the ambient conditions. Upon collision-induced dissociation (CID), characteristic fragments of the $[\mathrm{M}+\mathrm{Ag}]^{+} \mathrm{com}-$ plexes were identified for confident and sensitive detection of the four TBBPA derivatives. Under the optimized experimental conditions, the instrumental limits of detection (LODs) of TBBPA-BHEE, TBBPABGE, TBBPA-BAE and TBBPS-BAE were $0.37,0.050,0.76$, and $4.6 \mu \mathrm{g} \mathrm{L}^{-1}$, respectively. The linear ranges extended to $1000 \mu \mathrm{g} \mathrm{L}^{-1}\left(R^{2} \geq 0.9919\right)$, and the relative standard deviations (RSDs), inter-day variation and intra-day variation were less than $7.8 \%(n=9), 10.0 \%(n=5)$, and $14.8 \%$ ( $n=1$ per day for 5 days) for all derivatives. TBBPA derivative manufacturing industrial waste water, river water and tap water samples were fast analyzed with the proposed method. The contents of TBBPA derivatives were various in the collected samples, with the highest $19.9 \pm 0.3 \mu \mathrm{g} \mathrm{L}^{-1}$ of TBBPA-BAE in the waste water samples.
\end{abstract}

(C) 2014 Elsevier B.V. All rights reserved.

\footnotetext{
* Corresponding author. Tel.: +86 10 62849129; fax: +86 1062849129.

E-mail address: jbshi@rcees.ac.cn (J.-b.Shi).
}

\section{Introduction}

Tetrabromobisphenol A (TBBPA) and its derivatives are the most widely used brominated flame retardants (BFRs) [1,2], which are normally added with considerable amounts into a variety of plastic products, circuit boards, building materials and textiles to improve 
their fire resistance [3,4]. According to European Brominated Flame Retardant Industry Panel (EBFRIP), the global demand of TBBPA and its derivatives reached $170,000 \mathrm{t}$ in 2004 [1,5], and their production amount is more than 120,000 t/year [6]/150,000 t/year [7]. Pointed by World Health Organization (WHO), as much as $25 \%$ of this production is used to produce TBBPA derivatives [8], like tetrabromobisphenol A bis(allylether) (TBBPA-BAE), tetrabromobisphenol A bis(2-hydroxyethyl ether) (TBBPA-BHEE), tetrabromobisphenol A bis(glycidyl ether) (TBBPA-BGE) and tetrabromobisphenol $\mathrm{S}$ bis(allylether) (TBBPS-BAE), etc. [9]. These substances could easily enter the environment by waste water discharge of the TBBPA derivatives industry [10] and by using, disposal and recycling of the BFRs [11]. The debate on toxicity and bioaccumulation of TBBPA continues between scientists $[1,2,10,12]$. In contrast to TBBPA, a deep understanding of the environmental behavior and toxicity of the TBBPA derivatives is severely limited by the lack of efficient analytical methods $[1,10]$. Powerful analytical tools are imperative to rapidly detect these derivatives in real, complex environmental samples. The Panel on Contaminants in the Food Chain (CONTAM Panel) urges to collect the information of TBBPA derivatives on their production rates, use, chemical characteristics, occurrence in food and their long-term toxicity [10]. Consequently, the TBBPA derivatives become a hot focusing point of environmental researchers [9].

In a critical review, Covaci et al. pointed out that no data for detection of the derivatives was published before 2008 [1,13]. As a matter of fact, gas chromatography-mass spectrometry (GC-MS) is not practical for determination of these derivatives due to the instable thermal properties of these compounds [14]. Alternatively, electrospray ionization (ESI) and atmospheric pressure chemical ionization (APCI) are insufficient for quantitative detection of these derivatives in actual samples [1,14], because of their low proton affinities. Although TBBPA-BAE was successfully identified as an emerging neurotoxicant in environmental samples using high performance liquid chromatography-atmospheric pressure chemical ionization-mass spectrometry (HPLC-APCI-MS) [15], it was found that APCI was not sensitive enough to produce the molecular ions during the ionization. Active studies have been carried out by some groups to improve the feasibility of atmospheric pressure photoionization-mass spectrometry (APPI-MS) [14], APCI-MS [15] and HPLC-UV [16] for detection of these derivatives. The APPI-MS was more sensitive than other methods, with instrument detection limit of 12-112 pg for three TBBPA derivatives [14]. However, the need of a suitable dopant and the susceptibility of the mobile phase to ionization limited its applications. Therefore, additional analytical methods are still highly required to detect these derivatives.

Mass spectrometry are often preferred for environmental research [17-20], due to its premier sensitivity and unparalleled chemical specificity. Powered by ambient ionization techniques, analysis of actual samples with complex matrices is facile by mass spectrometry [21-25]. As reported in 2006, extractive electrospray ionization mass spectrometry (EESI-MS) was able to detect TNT in waste water, and trace atrazine in undiluted urine [26], showing promising applications in environmental studies. To date, EESI-MS has been applied to direct analysis of various samples, including exhaled human breath [27,28], skin [29], food [29-31], natural water [32], toothpaste [33], native proteins [34], etc. In this study, low ppb levels of TBBPA derivatives in waste water were detected for the first time with EESI-MS/MS.

\section{Experimental}

\subsection{Instrumentation}

All the experiments were carried out using a linear trap quadruple mass spectrometer (LTQ-XL, Thermo Fisher Scientific, San

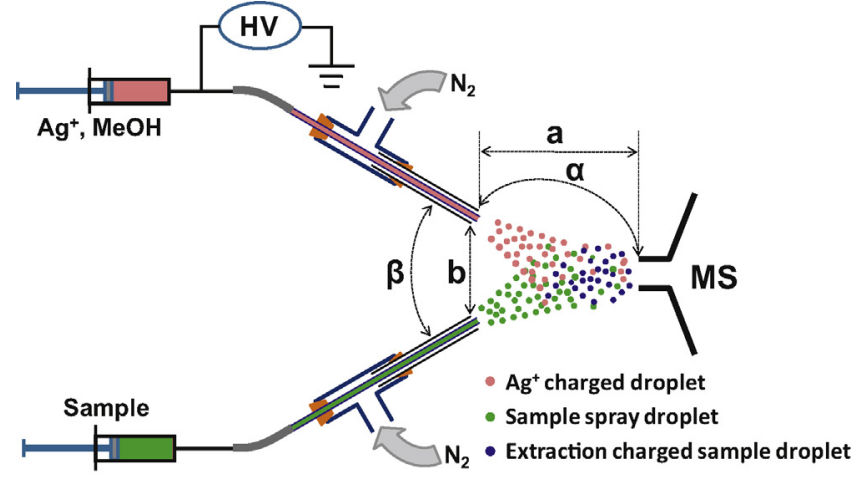

Fig. 1. The schematic illustration of $\mathrm{Ag}^{+}$reactive EESI-MS for the TBBPA derivatives detection. $\mathrm{Ag}^{+}, \mathrm{MeOH}$ : Silver nitrate methanol solution; HV: Positive high voltage $(+4 \mathrm{kV}) ; \mathrm{N}_{2}$ : Nitrogen; MS: LTQ-XL mass spectrometer; $a / b$ : distance between ES sprayer and MS/sample sprayer; $\alpha / \beta$ : angle between ESI and the MS inlet/the sample spray beam.

Jose, CA) installed with a homemade EESI source, which was previously described in detail [26,32-35]. The schematic illustration of EESI-MS is shown in Fig. 1. It was assembled by two sprayers, one sprayer was charged with high positive voltage $(+4000 \mathrm{~V})$ for silver nitrate methanol solution electrospray, the other one was used for sample nebulization. A silver nitrate methanol solution was injected by a syringe pump (Harvard) at a flow rate of $4 \mu \mathrm{L} \mathrm{min}^{-1}$ into the electrosprayer to generate active silver cations $\left(\mathrm{Ag}^{+}\right)$, which were accelerated by the electric field and vacuum system of the LTQ instrument to react with TBBPA derivatives, resulting in $[\mathrm{M}+\mathrm{Ag}]^{+}$complexes for mass analysis. The samples were also injected into the EESI system at flow rate of $4 \mu \mathrm{Lmin}^{-1}$ by another syringe ( $250 \mu \mathrm{L}$, Hamilton) and pump (equipped on the LTQ-MS). Nitrogen gas (1.2 MPa) was used for liquid nebulization. The temperature of the heated capillary of the LTQ-MS was maintained at $250^{\circ} \mathrm{C}$. The default values of voltages for the tube lenses, conversion dynode, detectors were directly used, no further optimization was performed. The syringes and sprayers needed to be rinsed thoroughly by de-ionized water and methanol, between samples to prevent contamination. In collision-induced dissociation (CID) experiment, the ions of interest were isolated with an $\mathrm{m} / \mathrm{z}$ width of 1 unit, Helium was used as the collision gas, and CID energy was $10-32 \%$ with a duration time of $30 \mathrm{~ms}$.

\subsection{Reagent and material}

All chemicals were used at least analytical grade. De-ionized water ( $18.2 \mathrm{M} \Omega \mathrm{cm}$, obtained by Milli- $Q$ water purification system, Billerica, USA) and methanol (HPLC grade, Fisher Scientific, Pittsburgh, US) were used for standard reagents and sample dilutions. HPLC grade and pesticide residue grade dichloromethane (DCM) were obtained from Fisher Scientific (Hampton, $\mathrm{NH}$ ) for sample extracting. $\mathrm{Na}_{2} \mathrm{SO}_{4}$ was prebaked at $660^{\circ} \mathrm{C}$ for $6 \mathrm{~h}$ before used for dehydration in sample preparation. Silver nitrate (Sinopharm Chemical Reagent Co., Ltd, analytical-reagent grade, China) was prepared in de-ionized water and diluted in methanol for $\mathrm{Ag}^{+}$ electrospray. TBBPA derivatives including TBBPA-BAE (CAS 2532789-3, 99\%), TBBPA-BHEE (CAS 4162-45-2, 98\%) and TBBPA-BGE (CAS 3072-84-2, purity unknown) were purchased from SigmaAldrich and purified with silica gel column chromatography before use. Tetrabromobisphenol S (TBBPS) was purchased from Beijing APIS Biotechnology Ltd. (Beijing, China). TBBPS-BAE was synthesized from TBBPS with a yield of $85 \%$. Briefly, TBBPS $(5.7 \mathrm{~g})$ and sodium hydroxide solution ( $0.8 \mathrm{~g}$ in $20 \mathrm{~mL}$ water) were dissolved in the solution of isopropanol/water $(10: 9)(20 \mathrm{~mL})$, then the mixture was reacted at $70^{\circ} \mathrm{C}$, and while allyl bromide $(2.2 \mathrm{~mL})$ was added 
dropwise to the solution in $5 \mathrm{~h}$. The reaction mixture was stirred for another $3 \mathrm{~h}$ at $78^{\circ} \mathrm{C}$. When the reagent was not detected anymore with thin layer chromatography (TLC), the reaction mixture was kept at room temperature until crystallization. The crystals were washed with water and recrystallized with ethyl acetate.

Tap water sample was obtained directly in the lab. The BFRs industrial waste water and river water samples were collected in Shandong Province (China) and stored at $4{ }^{\circ} \mathrm{C}$ before detection. After filtration through 0.45 membranes, $40 \mathrm{~mL}$ of sample solution was extracted by liquid-liquid extraction with $3 \times 20 \mathrm{~mL}$ of DCM. The extracts were dehydrated by $\mathrm{Na}_{2} \mathrm{SO}_{4}$, concentrated by rotary evaporator and nitrogen evaporator, and finally transferred into $1 \mathrm{~mL}$ methanol [15]. Before detection by EESI-MS, appropriate dilution by methanol was performed when necessary. The standard addition analysis of the water sample was performed by adding $0,40,80$ and $160 \mu \mathrm{g} \mathrm{L}^{-1}$ of TBBPA derivatives in the industrial waste water and by adding $0,2,4$ and $6 \mu \mathrm{g} \mathrm{L}^{-1}$ of TBBPA derivatives $(0,10,20$ and $30 \mu \mathrm{g} \mathrm{L}^{-1}$ for TBBPS-BAE) in the tap water and river water. Note that as the high matrix tolerance of EESI [26], gel permeation chromatography (GPC) clean up and SPE separation, which was normally required for HPLC and HPLC-APCI/APPI-MS [14,15], was not needed in the sample pretreatment.

\section{Results and discussion}

\subsection{EESI-MS spectrum of TBBPA derivatives}

Assumingly, the neutral aerosols of TBBPA derivatives collide with the charged silver nitrate micro-droplets, promoting the reaction of $\mathrm{Ag}^{+}$and TBBPA derivatives to form positively charged $[\mathrm{M}+\mathrm{Ag}]^{+}$complexes in the gas phase, which could be deeply characterized by tandem mass spectrometry. Following the procedure described in the experimental section, the full scan reactive EESI-MS spectra of $\mathrm{Ag}^{+}$and TBBPA-BHEE, TBBPA-BGE, TBBPA-BAE and TBBPS-BAE were recorded as shown in Fig. 2A-D (MS spectra between $m / z 500-1000$, see Fig. S1), respectively, showing dominant characteristic isotope peaks of the corresponding silver bound TBBPA derivatives. For example, the TBBPA-BHEE-silver and -bromide isotope ions $\left([\mathrm{M}+\mathrm{Ag}]^{+}\right)$dominated in the mass range of $m / z 735-m / z 745$ (Fig. 2A), with the centered signal ( $m / z 739$ and 741 ) up to $1.70 \times 10^{4} \mathrm{cps}$. Since both bromine and silver have two stable and almost equal abundance isotopes, i.e., ${ }^{79} \mathrm{Br}(50.7 \%)$ and ${ }^{81} \mathrm{Br}(49.3 \%),{ }^{107} \mathrm{Ag}(51.8 \%)$ and ${ }^{109} \mathrm{Ag}(48.2 \%)$, the isotopic distribution pattern of $[\mathrm{M}+\mathrm{Ag}]^{+}$should contain 6 isotope peaks and the proportion of abundance must be close to $1: 5: 10: 10: 5: 1$. As shown Fig. 2A, the peak number and the intensity ratio of the peaks at $m / z 735,737,739,741,743$ and 745 match the theoretic values, providing a strong evidence that the detections of TBBPA-BHEE derivatives were accomplished by forming $[\mathrm{M}+\mathrm{Ag}]^{+}$complexes by reactive EESI-MS

Similarly, TBBPA-BGE, TBBPA-BAE and TBBPS-BAE were also detected by silver reactive EESI-MS, resulting in dominant isotopic peaks of $[\mathrm{M}+\mathrm{Ag}]^{+}$complexes in Fig. $2 \mathrm{~B}$ and $\mathrm{C}$, in which the isotopic distribution pattern was well corresponding to the theoretic composition of the silver cationized TBBPA derivative. Note that the major isotope signal of TBBPA-BGE $\left(2.60 \times 10^{4} \mathrm{cps}\right)$ and TBBPA-BAE $\left(1.77 \times 10^{4} \mathrm{cps}\right)$ were higher than that of TBBPS$\operatorname{BAE}\left(2.37 \times 10^{3} \mathrm{cps}\right)$ at same concentration, probably because the $\mathrm{O}=\mathrm{S}=\mathrm{O}$ group, which is apt to withdraw electrons, in the TBBPS-BAE molecule reduced the possibility to form the $[\mathrm{M}+\mathrm{Ag}]^{+}$complexes under the experimental conditions. Therefore, a higher concentration $\left(2 \mathrm{mg} \mathrm{L}^{-1}\right)$ was used to achieve a better signal-to-noise isotope signal in Fig. 2D recorded for TBBPS-BAE analytes, indicating that tandem MS experiments where the chemical noise can be dramatically reduced would benefit the sensitive detection of the TBBPS-BAE.

\section{2. $M S / M S$ spectrum of TBBPA derivatives}

Although MS/MS data of these TBBPA derivatives is of great significance for analytical methodology development and further physical chemistry studies on the TBBPA derivatives, a literature survey showed that no data of these TBBPA derivatives was available. Therefore, collision-induced dissociation (CID) experiments
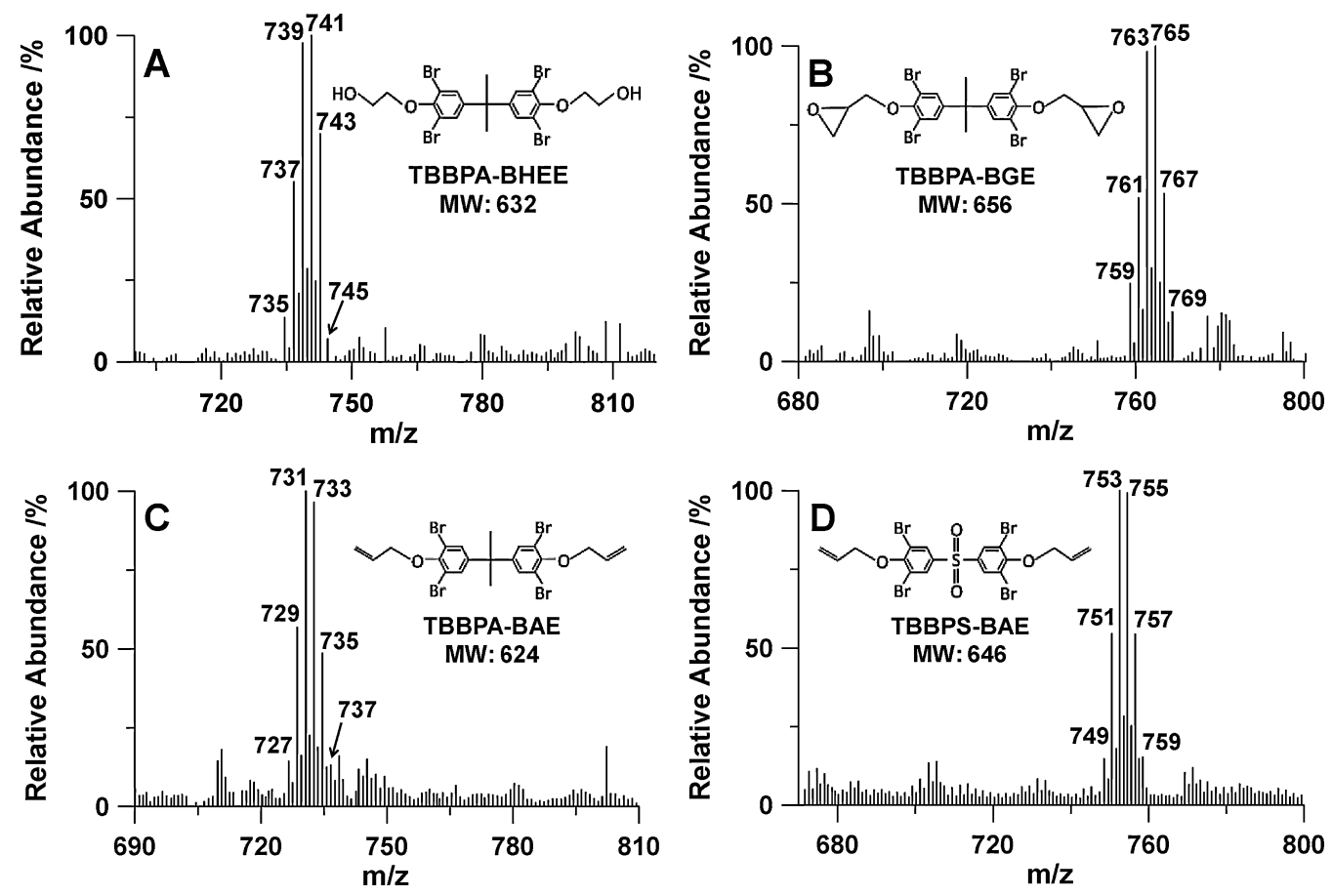

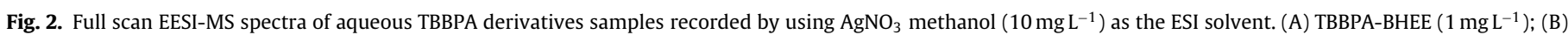
TBBPA-BGE ( $\left.1 \mathrm{mg} \mathrm{L}^{-1}\right)$; (C) TBBPA-BAE $\left(1 \mathrm{mg} \mathrm{L}^{-1}\right)$; (D) TBBPS-BAE $\left(2 \mathrm{mg} \mathrm{L}^{-1}\right)$. 

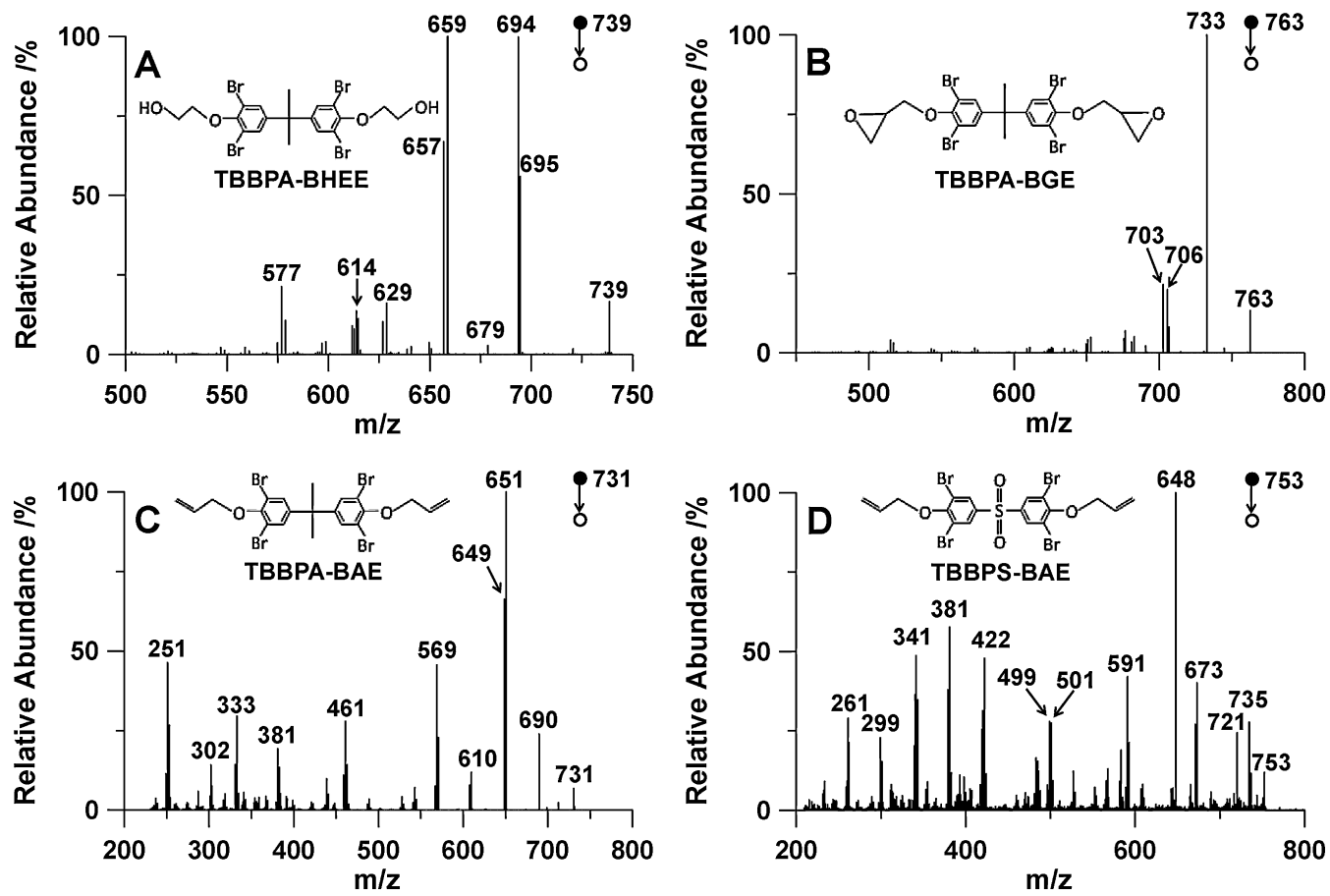

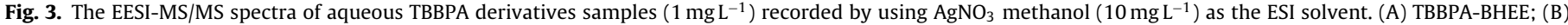
TBBPA-BGE; (C) TBBPA-BAE; (D) TBBPS-BAE.

were performed to the precursor ions: $m / z 739,763,731$ and 753 for TBBPA-BHEE, TBBPA-BGE, TBBPA-BAE and TBBPS-BAE. Upon CID with $20 \%$ collision energy, the precursor ions $(\mathrm{m} / z \mathrm{z} 39)$ generated major ionic fragments of $m / z 695,694,659,657,629$ and 577 (Fig. 3A), by the loss of $\mathrm{CH}_{2}=\mathrm{CH}-\mathrm{OH}, \cdot \mathrm{CH}_{2}-\mathrm{CH}_{2}-\mathrm{OH}, \mathrm{H}^{79} \mathrm{Br}$, $\mathrm{H}^{81} \mathrm{Br},\left[\mathrm{H}^{79} \mathrm{Br}, \mathrm{C}_{2} \mathrm{H}_{6}\right]$, and $\left[\mathrm{H}^{79} \mathrm{Br}, \mathrm{H}^{81} \mathrm{Br}\right]$, correspondingly. Small signals were also detected at $m / z 614$, which were obtained by the cleavage of $\left[\bullet \mathrm{CH}_{2}-\mathrm{CH}_{2}-\mathrm{OH}, \mathrm{HBr}\right]$ and $\left[\mathrm{CH}_{2}=\mathrm{CH}-\mathrm{OH}, \mathrm{HBr}\right]$ from the precursor ions ( $m / z 739)$. Refer to the CID results of TBBPA [36,37], the loss of isotopic species such as $\mathrm{H}^{79} \mathrm{Br}, \mathrm{H}^{81} \mathrm{Br}$, $\left[\mathrm{H}^{79} \mathrm{Br}, \mathrm{C}_{2} \mathrm{H}_{6}\right]$, and $\left[\mathrm{H}^{79} \mathrm{Br}, \mathrm{H}^{81} \mathrm{Br}\right]$ confirmed the successful detection of the precursor ions by reactive EESI-MS.

By applying $12 \%$ collision energy, the [TBBPA-BGE $+\mathrm{Ag}]^{+}$ions of $m / z 763$ lost $\mathrm{CH}_{2} \mathrm{O}$ species to yield a dominated fragment of $m / z 733$ in the MS/MS spectrum (Fig. 3B), in which as the small peaks at $m / z$ 706 and 703, was produced from the precursor ions $(\mathrm{m} / z \mathrm{z} 73)$ by the loss of $\left[\mathrm{CH}_{2} \mathrm{O}, \bullet \mathrm{C}_{2} \mathrm{H}_{3}\right]$ and $2 \mathrm{CH}_{2} \mathrm{O}$. Direct elimination of $\mathrm{H}^{79} \mathrm{Br}$ and $\mathrm{H}^{81} \mathrm{Br}$ from TBBPA-BAE silver cationized molecules $(\mathrm{m} / \mathrm{z} 731)$ was observed during the CID process with $12 \%$ collision energy, producing major fragments of $m / z 651$ and 649 (Fig. 3C). Other dissociation pathways in which neutral loss of $\left[\bullet \mathrm{CH}_{2} \mathrm{CHCH}_{2}, \mathrm{H}^{79} \mathrm{Br}\right]$, [ $\mathrm{H}^{79} \mathrm{Br}, \mathrm{H}^{81} \mathrm{Br}$ ], [2 $\mathrm{HBr}, \mathrm{AgH}$ ], [3HBr, $\mathrm{AgH}$ ], $\mathrm{C}_{9} \mathrm{H}_{7} \mathrm{OBr}_{2} \mathrm{Ag}$, [3HBr, $\mathrm{AgH}$, - Br] and $\mathrm{C}_{9} \mathrm{H}_{8} \mathrm{OBr}_{3} \mathrm{Ag}$ were also evidenced by the small peaks at $\mathrm{m} / \mathrm{z}$ $610,569,461,381,333,302$ and 251, respectively. However, the low intensities of these peaks indicate that the corresponding fragmentation pathways were not favored under the conditions. With relative high collision energy (30\%), the silver-TBBPS-BAE complex $(\mathrm{m} / z$ 753) fragmented intensively (Fig. 3D), allowing the production of a major peak at $m / z 648$ by the loss of $\left[\mathrm{SO}_{2}, \bullet \mathrm{CH}_{2}-\mathrm{CH}=\mathrm{CH}_{2}\right]$ and a series of small peaks at $m / z 735,721,673,591,501,499,422,381$, 341,299 and 261 by the cleavage of $\mathrm{H}_{2} \mathrm{O}, \mathrm{O}_{2}, \mathrm{H}^{79} \mathrm{Br},\left[\mathrm{H}^{79} \mathrm{Br}, \mathrm{H}^{81} \mathrm{Br}\right.$, $\left[\mathrm{H}^{79} \mathrm{Br},{ }^{107} \mathrm{AgH}, \mathrm{SO}_{2}\right],\left[\mathrm{H}^{81} \mathrm{Br},{ }^{107} \mathrm{AgH}, \mathrm{SO}_{2}\right],\left[{ }^{107} \mathrm{Ag}{ }^{81} \mathrm{Br}, \bullet^{79} \mathrm{Br}, \mathrm{SO}_{2}\right]$, $\left[\mathrm{H}^{79} \mathrm{Br},{ }^{107} \mathrm{Ag}{ }^{81} \mathrm{Br}, \mathrm{SO}_{2}, \mathrm{C}_{3} \mathrm{H}_{4}\right],\left[2 \mathrm{H}^{79} \mathrm{Br}, \mathrm{H}^{81} \mathrm{Br}, \mathrm{C}_{12} \mathrm{H}_{9} \mathrm{O}\right],\left[\mathrm{H}^{79} \mathrm{Br}\right.$, $\left.\mathrm{H}^{81} \mathrm{Br},{ }^{107} \mathrm{Ag}{ }^{81} \mathrm{Br}, \mathrm{SO}_{2}, \mathrm{C}_{3} \mathrm{H}_{4}\right]$ and $\left[2 \mathrm{H}^{79} \mathrm{Br}, \mathrm{H}^{81} \mathrm{Br},{ }^{107} \mathrm{Ag}{ }^{81} \mathrm{Br}, \mathrm{SO}_{2}\right.$, $\mathrm{C}_{3} \mathrm{H}_{4}$ ], respectively.

For better characterization of the $[\mathrm{M}+\mathrm{Ag}]^{+}$complexes, $\mathrm{MS}^{3}$, $\mathrm{MS}^{4}$ and $\mathrm{MS}^{5}$ spectrum of major fragment ions observed in the $\mathrm{MS}^{2}$ spectrum were also illustrated in the supporting information (Figs. S2-S5 and Tables S1-S4). The MS ${ }^{3}, \mathrm{MS}^{4}$ and $\mathrm{MS}^{5}$ data were in all good agreement with the molecular structure of the precursor ions, and experimentally provided systematic data evidences for unambiguous detection of the targeted TBBPA derivatives using EESI-MS.

\subsection{The interaction between $\mathrm{Ag}^{+}$and TBBPA derivatives}

In addition of using nitric silver as the reactive reagent, $\mathrm{Na}^{+}, \mathrm{K}^{+}$, $\mathrm{Cs}^{+}, \mathrm{H}^{+}$and $\mathrm{NH}_{4}{ }^{+}$was also tested to improve the ionization efficiencies of TBBPA derivatives, however, the complexes between these derivatives and adduct ions wasn't found in the MS spectrum. In order to investigate the complexation between $\mathrm{Ag}^{+}$and these derivatives, the probable structures and interaction energies $\left(-\Delta E_{0}\right)$ of complexes of TBBPA derivatives and $\mathrm{Ag}^{+}\left([\mathrm{M}+\mathrm{Ag}]^{+}\right)$ were calculated by Gaussian 03 system (details see $\dagger$ ESI; Table $\mathrm{S} 5$ ). As shown in Fig. S6, the $\mathrm{Ag}^{+}$combined with ether oxygen and bromine of the TBBPA derivative was the most possible configuration for $[\mathrm{M}+\mathrm{Ag}]^{+}$complexes. The interaction energies of TBBPA derivatives combined with $\mathrm{Ag}^{+}$were obtained between 51.24-61.90 $\mathrm{kcal} \mathrm{mol}^{-1}$, it further confirmed the TBBPA derivatives could combine with $\mathrm{Ag}^{+}$ions.

\subsection{Analytical performance}

Under the optimized experimental conditions, (i.e. high voltage, $+4000 \mathrm{~V}$; temperature of the heated capillary, $250^{\circ} \mathrm{C}$; nitrogen gas, $1.2 \mathrm{MPa}$; flow rate of sample $/ \mathrm{Ag}^{+}$solution, $4 \mu \mathrm{L} \mathrm{min}^{-1}$; angle $\alpha, 150^{\circ}$; angle $\beta, 60^{\circ}$; distance (a), $0.5 \mathrm{~mm}$; distance (b), $5 \mathrm{~mm}$, as illustrated in Fig. 1) tandem mass spectrometry experiments were performed to generate the characteristic fragments such as $m / z$ at 694, 733, 651 and 648 for quantitative detection of TBBPA-BHEE, TBBPA-BGE, TBBPA-BAE and TBBPS-BAE, respectively. Because the precursor ions were a member of the isotopic envelope of $[\mathrm{M}+\mathrm{Ag}]^{+}$ clusters, so these transitions were specific for quantification of the TBBPA derivatives. The calibration curve is illustrated in Fig. S7, and the results are summarized in Table 1 . The linearity ranges 
Table 1

The analytical performance of silver cation reactive EESI-MS for detection of TBBPA derivatives.

\begin{tabular}{|c|c|c|c|c|c|c|c|c|c|}
\hline TBBPA derivatives & $\begin{array}{l}\text { Precursor } \\
\text { ions }(m / z)\end{array}$ & $\begin{array}{l}\text { Product ions for } \\
\text { quantification }(\mathrm{m} / \mathrm{z})\end{array}$ & $\begin{array}{l}\text { Abundance ratios } \\
\text { of product ions }\end{array}$ & $R^{2 \mathrm{a}}$ & $\begin{array}{l}\text { Linear ranges } \\
\left(\mu \mathrm{gL}^{-1}\right)\end{array}$ & $\begin{array}{l}\operatorname{LODs}^{\mathrm{b}}\left(\mu \mathrm{g} \mathrm{L}^{-1}\right) \\
(S / N=3, n=11)\end{array}$ & $\operatorname{RSDs}(\%)^{c}$ & $\begin{array}{l}\text { Inter-day } \\
{\text { variation }(\%)^{\mathrm{d}}}^{\mathrm{d}}\end{array}$ & $\begin{array}{l}\text { Intra-day } \\
\text { variation (\%) }\end{array}$ \\
\hline TBBPA-BHEE & 739 & 694 & $\begin{array}{l}A_{m / z 659} / A_{m / z} 694 \\
85.1-128.1 \%\end{array}$ & 0.9919 & $1-1000$ & 0.37 & $3.1^{*}$ & 3.4 & 11.3 \\
\hline TBBPA-BGE & 763 & 733 & $\begin{array}{l}A_{m / z} 703 / A_{m / z} 733 \\
21.5-45.0 \%\end{array}$ & 0.9986 & $0.2-1000$ & 0.050 & $3.9^{*}$ & 10.0 & 10.4 \\
\hline TBBPA-BAE & 731 & 651 & $\begin{array}{l}A_{m / z} 690 / A_{m / z} 651 \\
22.8-39.9 \%\end{array}$ & 0.9928 & $2-1000$ & 0.76 & $7.7^{* *}$ & 8.5 & 14.1 \\
\hline TBBPS-BAE & 753 & 648 & $\begin{array}{l}A_{m / z} 673 / A_{m / z} 648 \\
23.4-53.5 \%\end{array}$ & 0.9985 & $15-1000$ & 4.6 & $7.8^{* * *}$ & 9.4 & 14.8 \\
\hline
\end{tabular}

a Coefficients of determination.

b LODs, instrument limits of detection.

c RSDs, relative standard deviations for successive detections.

d Relative standard deviation of inter-day detections, $100 \mu \mathrm{g} \mathrm{L}^{-1}, n=5$.

e Relative standard deviation of intra-day detections, $100 \mu \mathrm{g} \mathrm{L}^{-1}, n=1$ per day for 5 days.

$10 \mu \mathrm{g} \mathrm{L}^{-1}, n=9$.

** $20 \mu \mathrm{gL}^{-1}, n=9$.

*** $100 \mu \mathrm{g} \mathrm{L}^{-1}, n=9$.

Table 2

The TBBPA derivatives concentrations in real water samples detected by silver cation reactive EESI-MS.

\begin{tabular}{|c|c|c|c|c|}
\hline Water sample & TBBPA-BHEE $\left(\mu \mathrm{g} \mathrm{L}^{-1}\right)$ & TBBPA-BGE $\left(\mu \mathrm{gL}^{-1}\right)$ & TBBPA-BAE $\left(\mu \mathrm{g} \mathrm{L}^{-1}\right)$ & TBBPS-BAE $\left(\mu \mathrm{g} \mathrm{L}^{-1}\right)$ \\
\hline IW1 & $0.5 \pm 0.4$ & $1.3 \pm 1.1$ & $0.5 \pm 1.1$ & $0.5 \pm 0.6$ \\
\hline IW2 & $1.4 \pm 2.1$ & $4.9 \pm 2.6$ & $1.0 \pm 0.4$ & $8.2 \pm 2.7$ \\
\hline IW3 & $3.2 \pm 1.3$ & $3.2 \pm 1.9$ & $19.9 \pm 0.3$ & n.d. \\
\hline IW4 & n.d. & n.d. & $1.5 \pm 1.3$ & n.d. \\
\hline RW1 & $0.18 \pm 0.03$ & $0.07 \pm 0.03$ & $0.28 \pm 0.05$ & n.d. \\
\hline RW2 & $0.30 \pm 0.01$ & n.d. & $0.23 \pm 0.02$ & n.d. \\
\hline RW3 & $0.23 \pm 0.02$ & n.d. & $0.26 \pm 0.03$ & n.d. \\
\hline TW & n.d. & $0.03 \pm 0.05$ & n.d. & n.d. \\
\hline
\end{tabular}

IW1-4: industrial waste water; RW1-3: river water; TW: tap water.

n.d.: not detected.

extended to $1000 \mu \mathrm{g} \mathrm{L}^{-1}\left(R^{2} \geq 0.9919\right)$ for all TBBPA derivatives. By blank and standard solution direct injection, the instrumental limit of detection (LOD, $S / N=3, n=11$ ) was determined to be 0.37 , $0.050,0.76$, and $4.6 \mu \mathrm{g} \mathrm{L}^{-1}$ for TBBPA-BHEE, TBBPA-BGE, TBBPA$B A E$ and TBBPS-BAE, respectively. In comparison with the recent published data obtained by MS for detection of TBBPA derivatives, the LOD of this method for TBBPA-BAE detection was close to APPI-MS [14] (12 pg, $0.24 \mu \mathrm{g} \mathrm{L}^{-1}$ by our conversion) and much lower than that obtained by APCI-MS [15] $\left(2 \mu \mathrm{g} \mathrm{L}^{-1}\right)$ (LOD value was converted into same unit). More interestingly, the sensitivity of this method is even better than that of previously reported techniques, which provided LOD of $0.9 \mu \mathrm{g} \mathrm{L}^{-1}$ for TBBPA-BHEE and $0.8 \mu \mathrm{g} \mathrm{L}^{-1}$ for TBBPA-BAE using mesoporous cellular foams coating of solid-phase microextraction (SPME) [16]. The abundance ratios between the concomitant ions and the characteristic fragments (i.e., $A_{m / z} 659 / A_{m / z} 694, A_{m / z} 703 / A_{m / z} 733, A_{m / z} 690 / A_{m / z} 651$ and $\left.A_{m / z} 673 / A_{m / z} 648\right)$ were $85.1-128.1 \%, 21.5-45.0 \%, 22.8-39.9 \%$ and $23.4-53.5 \%$ for TBBPA-BHEE, TBBPA-BGE, TBBPA-BHEE and TBBPS-BAE detections in their linear ranges. These ratios are reasonable and are relevant for these TBBPA derivatives identification. For nine successive determinations of these four TBBPA derivatives standard solutions, the relative standard deviations (RSDs) were less than $7.8 \%$ for all TBBPA derivatives. The inter- and intra-day variations were less than $10.0 \%$ and $14.8 \%$ for five tests of $100 \mu \mathrm{g} \mathrm{L}^{-1}$ TBBPA derivatives in 1 day or for one test over 5 days.

\subsection{Real samples analysis}

Standard additions analysis was employed for quantitative analysis of the tap water, river water and industrial waste water samples. Typical MS and MS/MS spectra were obtained when adding standard TBBPA derivatives in these samples. Both the isotopic peaks of $[\mathrm{M}+\mathrm{Ag}]^{+}$complexes and characteristic fragments mass ions were received in these real samples detection. In order to minimize the matrix effects in the real samples, the standard addition analysis method was employed and the characteristic fragment ions were used to make the calibration curve for the TBBPA derivatives. The results were summarized in Table 2 , which showed the coefficients of determination were $\left(R^{2}\right) \geq 0.99$ for all samples, and the most common TBBPA derivative, TBBPA$B A E$ was detected in all of the four waste water samples up to $19.9 \pm 0.3 \mu \mathrm{g} \mathrm{L}^{-1}$ although TBBPA-BHEE and TBBPA-BGE were also found up to $3.2 \pm 1.3$ and $4.9 \pm 2.6 \mu \mathrm{g} \mathrm{L}^{-1}$, respectively, in three plants. As the newcomer of the TBBPA derivatives group, TBBPSBAE was also found up to $8.2 \pm 2.7 \mu \mathrm{g} \mathrm{L}^{-1}$ in waste water samples of two plants. The concentrations of derivatives in river waters were lower than in the waste waters. The maximum concentrations of $0.30 \pm 0.01 \mu \mathrm{g} \mathrm{L}^{-1}$ of TBBPA-BHEE, $0.07 \pm 0.03 \mu \mathrm{g} \mathrm{L}^{-1}$ of TBBPA-BGE, and $0.28 \pm 0.05 \mu \mathrm{gL}^{-1}$ of TBBPA-BAE were found in three different river waters. The concentration of TBBPA-BGE in the tap water from our lab was very low $\left(0.03 \pm 0.05 \mu \mathrm{g} \mathrm{L}^{-1}\right)$ and could be attributed to leaching of TBBPA-BGE from the plastic pipe in the water supply system. The error range was estimated by 3 times repeated detection and following the method described by Bruce et al. [38]. These data show that the EESI-MS is a useful tool for sensitive detection of the TBBPA derivatives, allowing advanced studies of TBBPA derivatives in environmental sciences and other related fields.

\section{Conclusion}

Silver cations $\left(\mathrm{Ag}^{+}\right)$generated by electrospraying a $\mathrm{AgNO}_{3}$ methanol solution ( $10 \mathrm{mg} \mathrm{L}^{-1}$ ) were employed for reactive ionization of TBBPA-BHEE, TBBPA-BGE, TBBPA-BAE and TBBPS-BAE in the EESI process, resulting in $[\mathrm{M}+\mathrm{Ag}]^{+}$complexes for post mass 
analysis by tandem mass spectrometry. The MS and MS/MS results of these derivatives were reported and discussed with details in this study. Under optimized conditions, the concentrations of TBBPABHEE, TBBPA-BGE, TBBPA-BAE and TBBPS-BAE were successfully determined in industrial waste water, river water and tap water samples. This work offers a practical solution for sensitive detection of low polar molecules such as TBBPA derivatives by EESI-MS ${ }^{n}$, and particularly promotes the environmental investigation in industry to completely understand the TBBPA derivative distribution and their environmental behaviors.

\section{Acknowledgements}

This research was supported by the National Natural Science Foundation of China (No. 21377155), the Chinese Academy of Sciences (No. YSW2013A01), and China Postdoctoral Science Foundation (No. 2013M530748). We Thank Teng-gao Zhu and Ning Xu for EESI and MS instrument assistance.

\section{Appendix A. Supplementary data}

Supplementary data associated with this article can be found, in the online version, at http://dx.doi.org/10.1016/j.aca.2014.01.035.

\section{References}

[1] A. Covaci, S. Voorspoels, M.A.-E. Abdallah, T. Geens, S. Harrad, R.J. Law, J. Chromatogr. A 1216 (2009) 346.

[2] T. Debenest, F. Gagne, A.N. Petit, C. Andre, M. Kohli, C. Blaise, Comp. Biochem. Phys. C 152 (2010) 407.

[3] C.A. de Wit, Chemosphere 46 (2002) 583.

[4] I. Watanabe, S. Sakai, Environ. Int. 29 (2003) 665.

[5] European Brominated Flame Retardant Industry Panel (EBFRIP), EBFRIP Questions Norwegian Proposal to Restrict the Use of TBBP-A and HBCD in Consumer Products, Statement, EBFRIP, June 4, 2007.

[6] H. Hakk, A Survey of tetrabromobisphenol A, in: Second International Workshop on Brominated Flame Retardants, BFR 2001, Stockholm University, Sweden, 2001

[7] P.A. Arias, Presented at the Second International Workshop on Brominated Flame Retardants BFR 2001, Stockholm, Sweden, May 14-16, 2001, p. 17.
[8] World health Organization, Environmental Health Criteria 172 Tetrabromobisphenol and Derivatives, World health Organization, Geneva, 1995.

[9] A. Bergman, A. Ryden, R.J. Law, J. de Boer, A. Covaci, M. Alaee, L. Birnbaum, M. Petreas, M. Rose, S. Sakai, N. Van den Eede, I. van der Veen, Environ. Int. 49 (2012) 57.

[10] European Food Safety Authority, EFSA panel on contaminants in the food chain (CONTAM); scientific opinion on tetrabromobisphenol A (TBBPA) and its derivatives in food, EFSA J. 9 (12) (2011) 2477, Available online 〈www.efsa.europa.eu/efsajournal〉.

[11] O. Segev, A. Kushmaro, A. Brenner, Int. J. Environ. Res. Pub. Health 6 (2009) 478

[12] W. Dekant, Risk Assessment of TBBPA: Updating the EU-Risk Assessment Reports, 2010, 〈http://www.ebfrip.org $\rangle$.

[13] A. Covaci, S. Harrad, M.A.E. Abdallah, N. Ali, R.J. Law, D. Herzke, C.A. de Wit, Environ. Int. 37 (2011) 532.

[14] R.J. Letcher, S. Chu, Environ. Sci. Technol. 44 (2010) 8615.

[15] G. Qu, J. Shi, T. Wang, J. Fu, Z. Li, P. Wang, T. Ruan, G. Jiang, Environ. Sci. Technol. 45 (2011) 5009

[16] X. Wang, J. Liu, A. Liu, Q. Liu, X. Du, G. Jiang, Anal. Chim. Acta 753 (2012)1.

[17] B. Domon, R. Aebersold, Science 312 (2006) 212.

[18] R.G. Cooks, K.L. Busch, G.L. Glish, Science 222 (1983) 273.

[19] J.B. Fenn, M. Mann, C.K. Meng, S.F. Wong, C.M. Whitehouse, Science 246 (1989) 64.

[20] K. Tanaka, H. Waki, Y. Ido, S. Akita, Y. Yoshida, T. Yoshida, Rapid Commun. Mass Spectrom. 2 (1988) 151

[21] R.M. Alberici, R.C. Simas, G.B. Sanvido, W. Romao, P.M. Lalli, M. Benassi, I.B.S Cunha, M.N. Eberlin, Anal. Bioanal. Chem. 398 (2010) 265.

[22] X. Ma, S. Zhang, X. Zhang, Trac-Trend. Anal. Chem. 35 (2012) 50.

[23] P. Nemes, A. Vertes, Trac-Trend. Anal. Chem. 34 (2012) 22.

[24] Z. Ouyang, X. Zhang, Analyst 135 (2010) 659.

[25] D.J. Weston, Analyst 135 (2010) 661.

[26] H.W. Chen, A. Venter, R.G. Cooks, Chem. Commun. (2006) 2042.

[27] H. Chen, A. Wortmann, W. Zhang, R. Zenobi, Angew. Chem. Int. Ed. 46 (2007) 580.

[28] M. Li, J. Ding, H. Gu, Y. Zhang, S. Pan, N. Xu, H. Chen, H. Li, Sci. Rep. 3 (2013).

[29] H. Chen, R. Zenobi, Nat. Protoc. 3 (2008) 1467.

[30] H.-W. Chen, B. Hu, X. Zhang, Chinese J. Anal. Chem. 38 (2010) 1069.

[31] L. Zhu, G. Gamez, H. Chen, K. Chingin, R. Zenobi, Chem. Commun. (2009) 559.

[32] M. Luo, B. Hu, X. Zhang, D. Peng, H. Chen, L. Zhang, Y. Huan, Anal. Chem. 82 (2010) 282.

[33] J. Ding, H. Gu, S. Yang, M. Li, J. Li, H. Chen, Anal. Chem. 81 (2009) 8632.

[34] H. Chen, S. Yang, M. Li, B. Hu, J. Li, J. Wang, Angew. Chem. Int. Ed. 49 (2010) 3053.

[35] H. Gu, N. Xu, H. Chen, Anal. Bioanal. Chem. 403 (2012) 2145.

[36] H. Gallart-Ayala, E. Moyano, M.T. Galceran, Rapid Commun. Mass Spectrom. 21 (2007) 4039.

[37] U.M. Schauer, W. Völkel, W. Dekant, Toxicol. Sci. 91 (2006) 49.

[38] G.R. Bruce, P.S. Gill, J. Chem. Educ. 76 (1999) 805. 